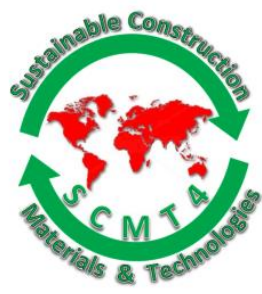

\title{
Water to Cement Ratio: A Simple and Effective Approach to Control Plastic and Drying Shrinkage in Concrete
}

\author{
Vasu Krishna1, and Rakesh Kumar ${ }^{2}$

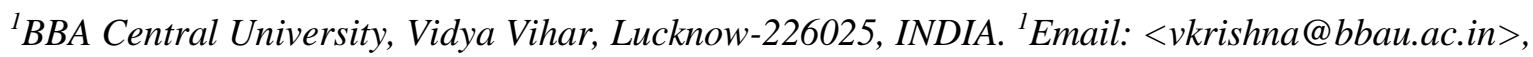 \\ ${ }^{2}$ Principal Scientist, Rigid Pavement Division, CSIR-Central Road Research Institute, Delhi-Mathura \\ Road, New Delhi- 100 025, INDIA. ${ }^{2 a}$ Email: 〈rakesh_crri@hotmail.com>.
}

\begin{abstract}
When water moves out of a porous body which is not fully rigid, contraction takes place. In Concrete, similar movement of water occurs from its fresh to hardened state which is known as Shrinkage. The loss of water by evaporation from the surface of the freshly laid concrete (i.e. plastic state) causes Plastic shrinkage. A similar loss can also occur by suction by the underlying subgrade or soil. Contracting of hardened concrete mixture due to loss of capillary water is called Drying Shrinkage. This shrinkage causes an increase in the tensile stress which may lead to cracking, internal warping and deflections. Several factors affect the plastic and drying shrinkage including temperature, water / cement ratio, curing materials and time. Concrete exhibiting high shrinkage can lead to serviceability problems in structures due to excessive deflections or warping (curling); if higher shrinkage leads to cracking, durability of the structure may also be impaired. Several studies and investigations have demonstrated that adequate and proper curing of concrete is the most appropriate step to prevent shrinkages and developing a high degree of the desirable properties of concrete. The best curing techniques and procedures depend upon the watercement ratio of the concrete. This paper highlights the causes of the plastic and drying shrinkages with easier approaches to avoid or minimise them so as to prevent deterioration of concrete.
\end{abstract}

\section{INTRODUCTION}

Shrinkage is one of the most detrimental properties of concrete, which affects the long-term strength and durability. It can result in severe cracking that facilitates the penetration of aggressive ions and renders the reinforcing steel more vulnerable to rusting. As a result the durability of the concrete structures can be severely compromised and their life cycle will be minimised drastically when shrinkage results in severe cracking. Therefore it is important to understand how to control the cracking due to shrinkages. To do this, it is essential to understand its origin (or types) and causes. Major types of shrinkages in concrete are Plastic, Drying, Autogenous, Carbonation and Thermal. However, only Plastic and Drying srhionakge are discussed in this paper. 
Plastic Shrinkage manifests itself soon after the concrete is placed in the forms while the concrete is still in the plastic form. Loss of water by evaporation from the surface of concrete or by the absorption of aggregates or subgrade is believed to be the reason of plastic shrinkage causing cracks. These are cracks that start to form before the concrete has set (i.e. is still 'plastic'), but which may not become parallel to each other. They are typically 300 to $600 \mathrm{~mm}$ long and up to $3 \mathrm{~mm}$ wide (Neville, 2012). Although often quite small and shallow initially, subsequent loading can cause the cracks to increase in size. Drying Shrinkage is unavoidable unless concrete is completely placed in water or exposed to 100 per cent relative humidity.

However it is impossible to do thus drying shrinkage is a serious phenomenon that routinely occurs and merits care full consideration in the design and construction of concrete structures. Autogenous shrinkage is due to with-drawl of water from the capillary pores by the hydration of the remaining unhydrated cement (Self Desiccation process). This type of shrinkage is relatively small, except at extremely low water cement ratios and for practical purposes need not to be distinguished from shrinkage caused by drying out of concrete (Neville, 2012). $\mathrm{CO}_{2}$ present in the atmosphere can react with the hydrated cement of the concrete. During this calcium hydroxide is converted into calcium carbonate and also some cement compound decomposes. This results in the Carbonation Shrinkage.

Studies of numerous investigations have conclusively demonstrated that adequate and proper curing of concrete can reduce the shrinkage effects. Proper and adequate curing is the best measure to minimize the shrinkages in the concrete (Pierre-Claude Aitcin, 2011). Curing becomes of particular importance where water-tightness and durability under severe conditions of exposure are required. Also low w/b (water/binder) ratio concretes do not contain enough mixing water to fully hydrate cement and supplementary cementitious materials. Curing mitigates the shrinkage development in low w/b concretes and reduces the risk of early cracking (Pierre-Claude Aitcin, 2011).

There are simple approaches to prevent dry and plastic shrinkage provided that characteristics of concrete mixes, the ambient conditions, job site conditions and water-cement ratio should be considered properly by the engineers

\section{PLASTIC SHRINKAGE: AN OVERVIEW}

Loss of water from fresh concrete, which leads to plastic shrinkage, can occur in a couple of ways. The predominant mode is, however, through evaporation from an exposed surface. Concrete can also loss water through suction by the sub base or, depending on the type of material used in its manufacture, the formwork etc. Such loss of water can aggravate the effects of surface evaporation. It is generally accepted that the loss of water from the paste fraction of concrete due to external factors generates negative capillary pressures that cause the volume of the paste to contract, hence the shrinkage. The rate of water evaporation is usually aggravated by a combination of high wind speed, low relative humidity, high ambient and concrete temperatures and cement content of the mix. Though these conditions are most likely during the summer months, they can occur at any time.

Figure 1 shows the variation of plastic shrinkage due to different atmospheric conditions: The rate at which bleed water is transported to the concrete surface will impact the potential for the phenomenon or form of cracking commonly referred as plastic shrinkage cracking. It has been reported (CTU-Shrinkage of Concrete, 2012) that if the rate of surface evaporation exceeds about $0.1 \mathrm{Ib} / \mathrm{ft} 2 / \mathrm{h}\left(0.5 \mathrm{~kg} / \mathrm{m}^{2} / \mathrm{h}\right)$, the loss of moisture may exceed the rate at which bleed water reaches the surface, thereby setting into motion the mechanisms that cause plastic shrinkage. Figure given below shows plastic shrinkage of concrete: 


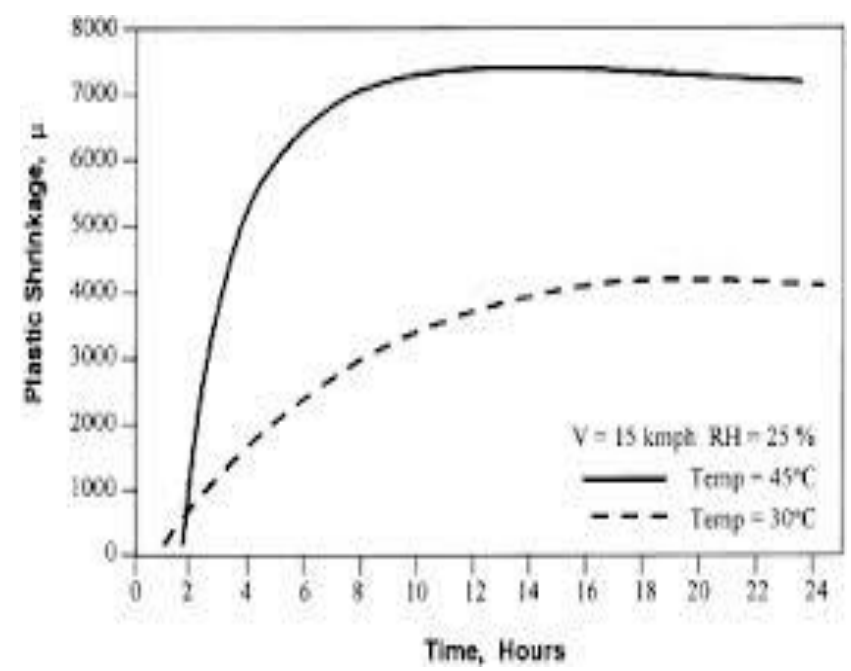

Figure 1. Factors of Plastic Shrinkage (Science direct, 2010) Note: W/C ratio is 0.40

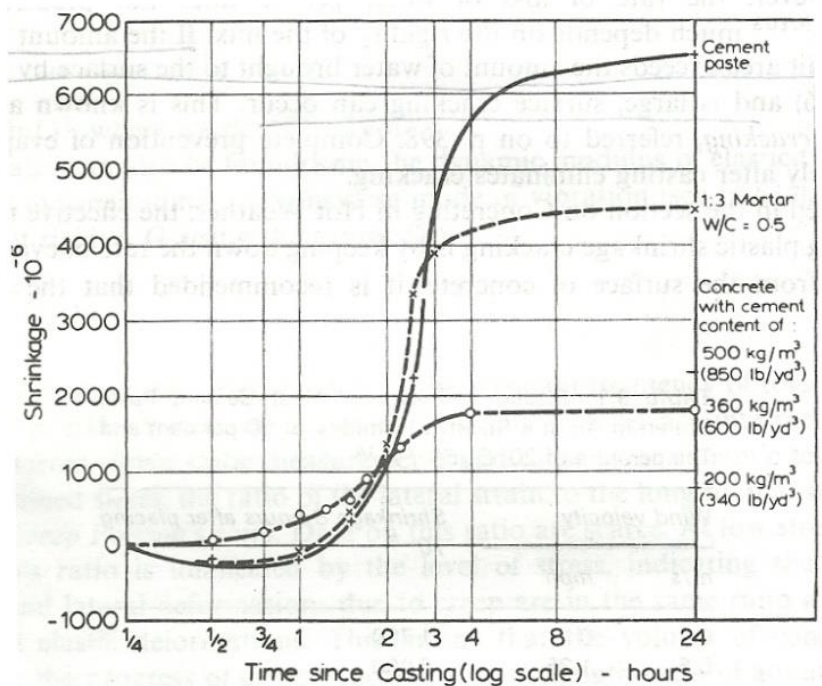

Figure 2. Effect of cement content on Plastic Shrinkage (Neville, 2012)

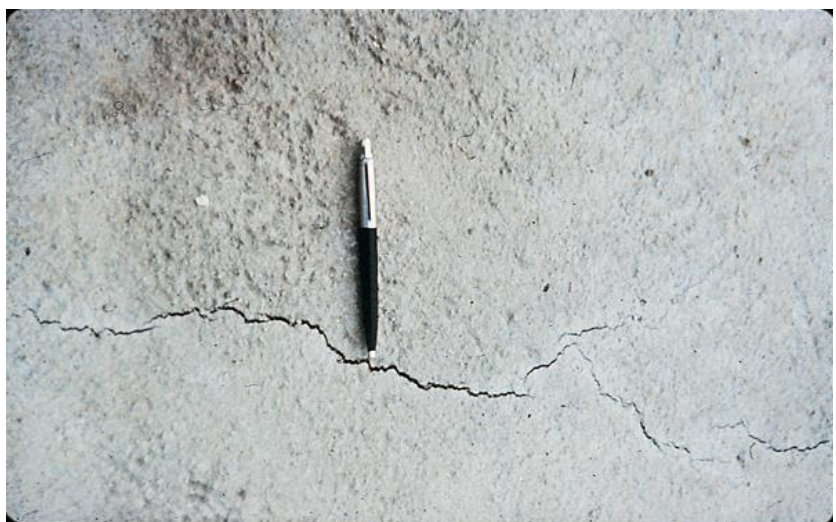

Figure 3. A typical plastic shrinkage crack (Cement Concrete \& Aggregate, 2002, (http://www.astm.org/DIGITAL_LIBRARY/JOURNALS/CEMENT/TOC/2412002.htm) 


\section{DRYING SHRINKAGE: AN OVERVIEW}

When concrete is exposed to its service environment it tends to reach equilibrium with that environment. If the environment is a dry atmosphere the exposed surface of the concrete loses water by evaporation. The rate of evaporation will depend on the relative humidity, temperature, water-cement ratio, area of the exposed surface of the concrete, aggregate content etc. The figure given below can illustrate these.

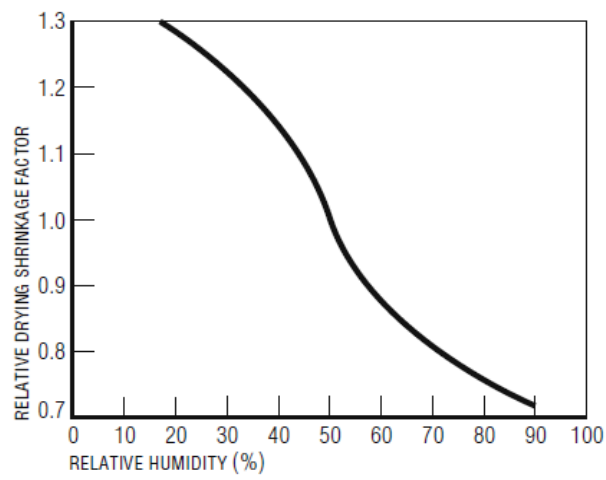

Figure 4. Effect of Relative humidity on drying shrinkage (Cement Concrete \& Aggregate, 2002, http://www.astm.org/DIGITAL_LIBRARY/JOURNALS/CEMENT/TOC/2412002.htm)

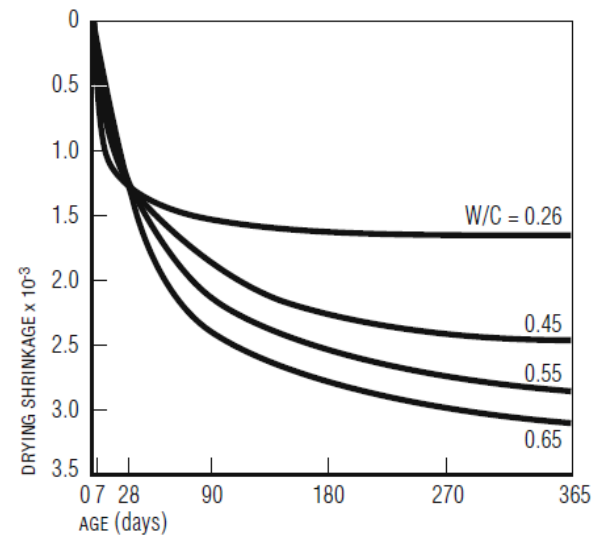

Figure 5. Effect of W/C on drying shrinkage. (Cement Concrete \& Aggregate, Aus., 2002, http://www.astm.org/DIGITAL_LIBRARY/JOURNALS/CEMENT/TOC/2412002.htm)

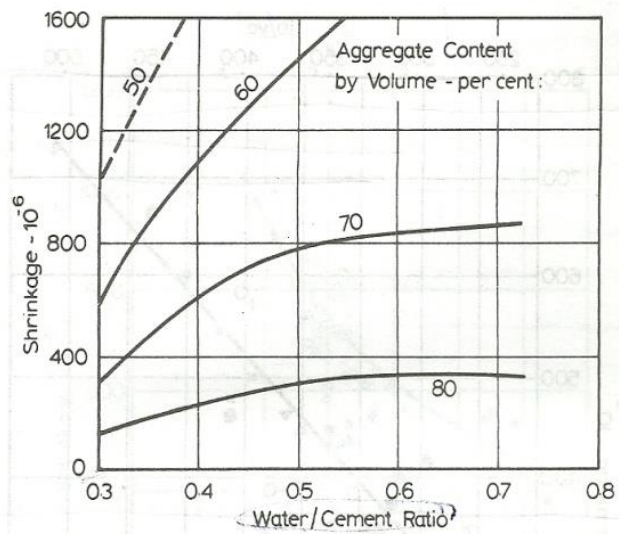

Figure 6. Effect of Aggregate content on Drying Shrinkage (Neville, 2012) 
The first water to be lost is that held in the large capillary pores of the hardened concrete. The loss of this water does not cause significant volume change. However as drying continues, loss of water from small capillary pores and later from gel pores takes place. With the reduction in the vapour pressure in the capillary pores, tensile stress in the residual water increases. Tensile stresses in the capillary water are balanced by compressive stresses in the surrounding concrete and a result concrete shrinks. Evaporation of gel water changes the surface energy of the solid phase and causes further shrinkage. Drying shrinkage makes up a portion of the total deformation that is observed in a concrete member.

\section{W/C RATIO FOR HYDRATION OF CEMENT}

Power's work (1947) is considered to be pioneer on the hydration of cement paste. Jansen \& Hansen (2001) summarized the work of power in a very relevant manner. It is to be noted that fully hydration of cement is very much necessary for the strength development, shrinkage prevention and thus durability of the concrete. The hydration of cement depends upon the W/C ratio of the concrete. When the W/C ratio is more than 0.42 , there will be greater capillary water and the greater the volume of capillary network.

This reduces the strength and durability of the concrete. Theoretically, when there is an external source of water (i.e. for curing), full hydration can be reached at $0.36 \mathrm{~W} / \mathrm{C}$ ratio. When concrete has W/C ratio equals to 0.36 and is water cured (internal or external), full hydration will reach and there will be no capillary water. The concrete will be a compacted solid composed of cement gel and gel water. This will be the best concrete we are looking for in our quest to durability. When the $\mathrm{W} / \mathrm{C}$ ratio is below 0.36, compressive strength continues to increase in spite of the fact that it is always the same amount of cement that hydrates (corresponding to $0.36 \mathrm{~W} / \mathrm{C}$ ). This increase in strength is due to closeness of the cement particles. In spite of rapid gain in compressive strength, concrete of W/C ratio less than 0.36 develops Autogenous shrinkage (in the absence of water curing). This decreases the durability of the structure.

\section{W/C RATIO: FUNCTION OF CURING}

Curing is the best procedure to reduce the effects of plastic and drying shrinkages. Curing prevents the loss of moisture from concrete and, when needed, supply additional moisture and maintain favourable concrete temperature for sufficient period of time. However while choosing the best curing procedures for any concrete structures, the water-cement ratio must be considered, as follows:

\section{When $\mathrm{W} / \mathrm{C}>0.42$}

0.42 is a critical w/c ratio (Pierre et al, 2011). Concrete having w/c ratio more than 0.42 , contain sufficient water to fully hydrate the Portland cement. Thus, in order to take all the binding potential of this cement, it is necessary to keep this water inside the concrete as long as possible. Preventing the evaporation of this water is the best means of providing good curing conditions for such concretes. Layer of impervious layer can prevent the loss of water by evaporation. However it is to be noted that greater the w/c ratio, the greater the capillary porosity, the larger the pores and the easier evaporation of the water. Easy drying means higher drying shrinkage, and thus more cracking. The greater the w/c ratio, the greater the vulnerability of concrete. Thus when w/c ratio is greater than 0.42 , the mixing water should be keep inside as long as possible.

\section{When W/C between 0.36-0.42}

According to Jensen and Hansen (2001), if some additional water is introduced into a hardening cement paste of w/c between 0.36 and 0.42 , full hydration can be achieved. To properly cure concrete having w/c ratio between 0.36 and 0.42 , it is necessary to provide some additional water within the hardening paste of concrete to fully hydrate the cement and prevent the shrinkages. This can be achieved through Internal Curing. 


\section{When W/C $<0.36$}

Concrete having w/c ratio less than 0.36 must be water cured. If these are not water cured, at the end of hydration process they contain a very fine porosity filled with air and water vapour due to chemical contraction of the paste (Pierre et al, 2010). Thus concrete having a w/c ratio less than 0.36 must be water cured not to improve the hydration condition but rather to mitigate and counteract the effect of plastic and drying shrinkages.

\section{MITIGATING PLASTIC SHRINKAGE}

Plastic shrinkage occurs due to loss of water contained in the fresh concrete. It can be prevented by covering the concrete with an impervious layer or providing some external water depending upon the $\mathrm{W} / \mathrm{C}$ ratio. There are several means to achieve this.

\section{When W/C $>0.42$}

Liquid applied evaporation reducers: Evaporation reducers (ACI 308R-13) are organic solutions that are capable of producing a monomolecular film over the bleed layer of water that raises to the top surface of concrete. If present in sufficient concentration, these chemicals form an effective film that reduces the rate of evaporation of the bleed water from the concrete surface. Evaporation reducers can be sprayed onto freshly placed concrete to reduce the risk of shrinkage when the evaporation rate equals or exceed the bleeding rate. Evaporation reducers are not to be used for the purpose making it easier to finish concrete surfaces and should be used only in accordance with manufacturer's instruction. But it is important to note that curing membranes must not be used with concrete having w/c ratio lower than 0.42 , because later on this membrane will prevent the penetration of additional water to mitigate autogenous shrinkage and early cracking risks, except when some form of internal curing is provided.

\section{When W/C between 0.42-0.36}

Fogging: It provides excellent protection against surface drying when applied properly and frequently and when the air temperature is well above freezing. Fogging requires the use of an inexpensive but specially designed nozzle that atomizes the water into a fog like mist. The basic purpose of the fogging is to increase the humidity of the air and reduce the rate of evaporation which can help in mitigating the Plastic Shrinkage. It should be remembered that fogging process should be done continuously in order to avoid the loss of humid atmosphere. However It is to be noted that fogging can be used to prevent plastic shrinkage with any concrete whatever its w/c ratio (Pierre, 2010). Curing compounds can also be used in this case but it should also be accompanied by internal curing.

\section{When W/C $<0.36$}

Water spraying, Ponding or the use of water saturated blankets or geotextiles can be used to prevent plastic shrinkage when water cement ratio is less than 0.36 . This external water not only prevents the formation of menisci in the porosity but also hydrates some unhydrated cement particles. Ponding is used for slabs, such as culvert floors or bridge decks, pavements, flat roofs, or wherever a pond of water can be created by a ridge, dike, or other dam at the edge of the slab.

\section{Preventing drying shrinkage}

Drying shrinkage cracking is only concern with concretes having a w/c ratio greater than $\mathbf{0 . 4 2}$ (Pierre, 2010). These concretes contain more water than necessary to fully hydrate the cement, and they have a 
well-connected capillary porosity; the greater the w/c, the larger and better connected this porosity is. So when these concretes dry, water evaporates and due to the resulting tensile forces menisci increases. Water curing only delays the time at which w/c $>0.42$ concrete will begin to shrink due to drying (Cement Concrete and Aggregate, Aus., 2002). Drying shrinkage can be mitigated using shrinkage reducing admixtures that reduces the surface tension in the menisci. Drying shrinkage of the concrete can also be reduced by increasing the content of coarse aggregate. According to Neville (1995), an aggregate volume of $30 \%$ reduces by half the shrinkage of the mixture. It is to be noted that whatever the aggregate content is, the shrinkage of cement paste remains same; it is the shrinkage of the concrete that is reduced. The aggregate skeleton only restrains the shrinkage of the paste

\section{Effect of curing time on Shrinkage}

The duration of curing is very much essential to prevent the shrinkage effects on concrete. The duration of curing is sensitive to the w/c of the pastes because a lower w/c results in closer initial spacing of the cement particles, requiring less hydration to fill interparticle spaces with hydration products (ACI 308R01). For concrete with and without pozzolonas and chemical admixtures, a 7-day minimum curing is required to attain the desirable characteristics and prevention of shrinkages. But it is not necessarily true as certain cement and admixtures combinations will extend the time required.

\section{CONCLUSION}

- Concrete curing is as important as the w/c ratio for durable and sustainable concrete.

- The most suitable W/C ratio for complete hydration of cement is 0.36 . The complete hydration is necessary for strength development, shrinkage prevention.

- Concrete having w/c ratio greater than 0.42 , should have sufficient mixing water inside so as to prevent Drying shrinkage effect. It can be prevented by fogging by using more amount of coarse aggregate, shrinkage reducing admixtures.

- For Concrete having a lower w/c ratio, it is important to provide some additional water so as to prevent the Plastic Shrinkage.

- Curing concrete is a long-term investment that does not cost very much: it lengthens the active life of the concrete structure, and is intimately associated with sustainability

\section{REFERENCES}

AASHTO M148, “Liquid membrane forming curing compound.”, AASHTO material standards.

ACI 308R (2001). "Guide to Curing Concrete", American Concrete Institute.

Alawode O., Dip P. G., Idowu O. I. (2011). "Effect of Water Cement Ratio on the Ccompressive Strength and Workability of Concrete and Laterite Concrete Mixes." The Pacific Journal of Science and Technology, 12(2), 99-105.

Byard B., Schindler A., and Barnes R. (2012). "Early-Age Cracking Tendency and Ultimate Degree of Hydration of Internally Cured concrete." ASCE Journal of Materials in Civil Engineering, 24(8),10251033.

Concrete Technology Update (2012). "Shrinkage of Concrete." Master Builder, BASF Chemicals.

http://59.167.233.142/publications/pdf/DryingShrinkage.pdf, "Drying shrinkage of Cement and Concrete." Cement Concrete and Aggregate, Australia. 
Jensen O., and Hansen E. (2001). "A Model for the Microstructure of Calcium Silicate Hydrate in Cement paste." Cement and Concrete Research, 30(1),101-116.

Lopez. M., Kahn L. F., and Kurtis K. E. (2010). "High Strength Self-curing Low Shrinkage Concrete for Pavement Applications." International Journal of Pavement Engineering, 11(5), 333-342.

Manual of NRMCA (1998). "CIP-5 Plastic Shrinkage Cracking." <http://www.nrmca.org/aboutconcrete/cips/05p.pdf> (Oct. 10, 2015).

Neville A.M. (2012), "Properties of Concrete." Cement Concrete and Aggregate, Australia, 4, 423-435.

Orchard D. F. (1990). “Concrete Technology.”2, 181-198.

Pierre-Claude Aitcin, Sidney Mindness (2011), "Sustainability of concrete." Vol. 1, pp. 212-223.

Qiao P., McLean D., Zhuang j. (2010), "Mitigation strategies for early age shrinkage cracking in Bridges Decks." WSDOT, USA.

Snell M. Luke (2009), "Prevention of plastic shrinkage cracks." Del E. Webb School of construction, Arizona State University, Tempe, Arizona.

Soliman A. M.(2011). "Early age shrinkage of Ultra high performance Concrete.”, Department of Civil \& Environmental Engg, University of Ontario, http://ir.lib.uwo.ca/cgi/viewcontent.cgi? article $=1226 \&$ context $=$ etd $($ Oct. 5, 2015).

Uno J. P. (1998). "Plastic Shrinkage Cracking and Evaporation Formulas.", ACI Material Journal, 95(4), 365-374.

Wang Kejin, Cable K. James, Ge Zhi (2006). "Evaluation of Pavement Curing Effectiveness and Curing Effect on Concrete Properties." ASCE Journal of Materials in Civil Engineering, 18(3), 377-389. 